\title{
Research on Dissipation and Fatigue Capacity of Nonstiffener Shear Panel Dampers
}

\author{
Ji-long Li, ${ }^{1,2,3}$ Ya-nan Tang, ${ }^{2}$ and Xuan-ming Liu ${ }^{2}$ \\ ${ }^{1}$ Ministry of Education Key Laboratory of Structural Engineering Disaster and Control, Harbin Institute of Technology, \\ Harbin, Heilongjiang 150090, China \\ ${ }^{2}$ Department of Civil Engineering, Harbin Institute of Technology, Harbin, Heilongjiang 150090, China \\ ${ }^{3}$ Department of Civil and Environmental Engineering, University of California, Berkeley, CA 94710, USA
}

Correspondence should be addressed to Ji-long Li; lijilong@hit.edu.cn

Received 18 May 2015; Revised 7 August 2015; Accepted 9 August 2015

Academic Editor: Hossein Moayedi

Copyright (C) 2015 Ji-long Li et al. This is an open access article distributed under the Creative Commons Attribution License, which permits unrestricted use, distribution, and reproduction in any medium, provided the original work is properly cited.

Passive energy dissipation control system can effectively control structure response under seismic action. As a form of passive energy dissipation control, yielding steel shear panel dampers can dissipate energy of the ground motion very well with the plastic deformation. By monotonic cyclic loading, hysteretic performance of the $15 \mathrm{~mm}$ thick core-board nonstiffener shear panel damper is tested, and the test shows that the damper has a superior hysteretic performance. Using finite element analysis software ABAQUS, and taking height to thickness ratio of the core-board as variable, the qualitative analysis on the damper is carried out, and results show that the critical height to thickness ratio of shear panel damper is between 30 and 35 . Three groups of $15 \mathrm{~mm}$ thick core-board nonstiffener shear panel dampers are tested by constant amplitude cyclic loading under different amplitudes; the results show that the fatigue performance is fine and the damper is a good energy dissipation device.

\section{Introduction}

Research and application of structure vibration control in civil engineering has been carried out more than 40 years ago [1], which is brought up by the Japanese scholars Kobori and Minai [2] and the American scholar Yao [3], respectively, in the 60 s and 70 s of 20 th century, and then a large number of scholars have made further researches on it. In recent years, many structural vibration control devices have been applied to the wind, waves, and seismic response control. Structure vibration control mainly includes three aspects: base isolation, passive vibration isolation $[4,5]$, and active and semiactive intelligent control. Although the base isolation is able to control the structure vibration, once it is damaged or reaches fatigue limit, the replacement is difficult and expensive. Active, semiactive, and intelligent control is an ideal mode of vibration control; however, the complex control system and large energy driving pattern make the application greatly inconvenient. Passive energy dissipation damper does well in controlling the vibration of the structure; with its low cost, convenience to be replaced, and simple control system, it is an ideal vibration control mean in recent years.

Passive energy dissipation damper is to install energy dissipation elements of nonstructural component [6] in the structure, thus dissipating the energy of structure vibration and reducing the structural vibration response. Energy dissipation components in general can be divided into three kinds [5]: displacement related type, speed related type, and tuned vibration absorption type. Shear panel damper is a kind of displacement related type energy dissipation component, which dissipates the energy via elastic-plastic deformation of metal materials [7]. In recent years, the shear panel damper has been widely used in building structures [8], of which there are two kinds of arrangements, brace type and column type, as shown in Figure 1. In the early years, the core-board is mainly made of structural steel (mild steel) with the lower yield, such as North America A36, Japan SS400, and China Q235. These mild steels have the yield stress between $235 \mathrm{MPa}$ and $300 \mathrm{MPa}$, whose ductility can reach about $30 \%$. Test and actual application show that mild steel damper has the higher 


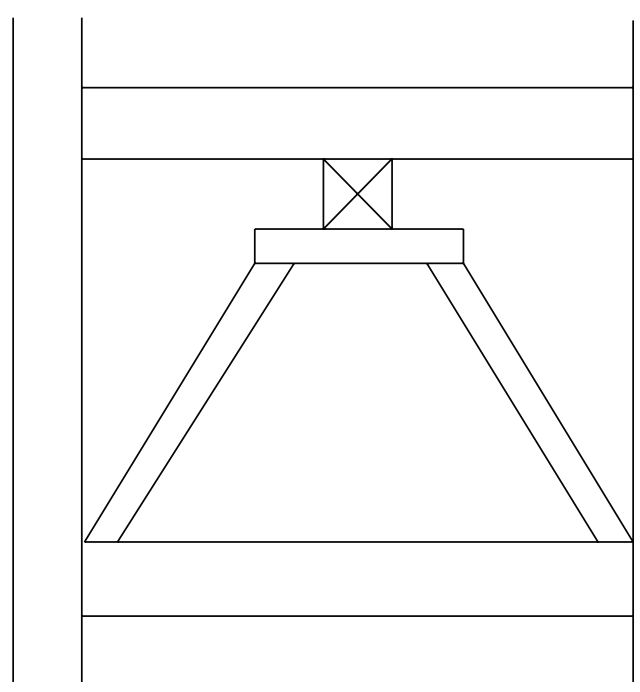

(a) Brace type
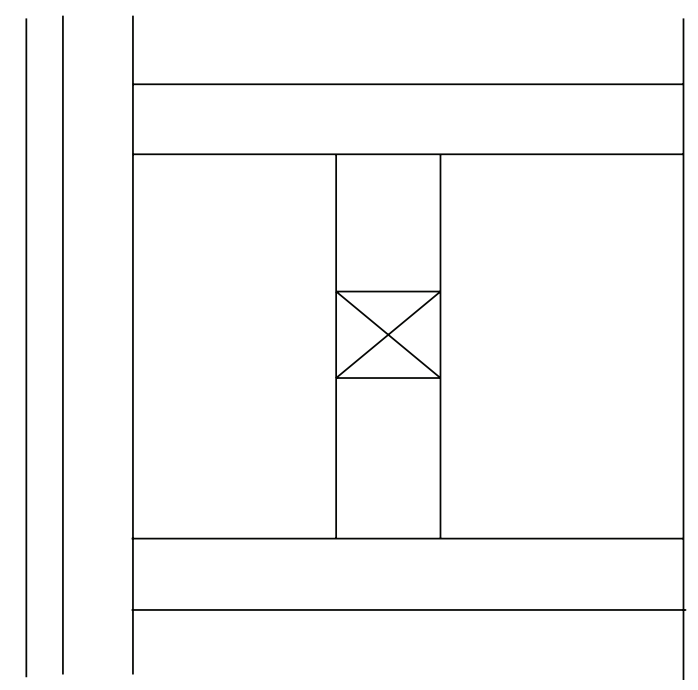

(b) Column type

FIGURE 1: Application of shear panel damper in buildings.

yield strength, and damping effect is not obvious during the small earthquake and wind vibration. To solve the problem, researches have been made in Japan firstly to use ultra-low yield stress steel with the yield strength less than $100 \mathrm{MPa}$ $[9,10]$ as seismic dampers $[11,12]$ and obtain good effect $[13,14]$. The damper made of low yield point will yield firstly and absorb energy with repeated deformation to protect major structure when suffering the earthquake [15]. In China [16-18], the development and application of lowyield-point steel did not start until 2005; Shanghai Baosteel independently developed ultra-low yield strength steel with the yield stress between $100 \mathrm{MPa}$ and $225 \mathrm{MPa}$, including BLY100, BLY160, and BLY225. Since then domestic low-yieldpoint steel basically reaches the performance requirements of Japanese production. Figure 2 illustrates the comparison of stress-strain relationship between BLY100, SS400 (Q235), and SM400 (Q345).

Nowadays, the research on low-yield-point steel shear panel damper is mainly focused on the theory analysis and finite simulation; the experimental research is still rare, especially in the study on fatigue performance. Since 2009, Zhongshuang $[19,20]$ tests the performance of shear panel damper made of low point steel; the results based on the skeleton curve and equivalent viscous damping coefficient show that this type of damper is an ideal equipment of energy dissipation. With this premise, two batches of nonstiffened shear panel damper are made of domestic low-yield-point steel. One batch is used to test hysteretic performance through monotonic cyclic loading, and the other batch is used to test fatigue performance through constant amplitude cyclic loading. By using finite element analysis software ABAQUS, with the height to thickness ratio of core-board as variable, combined hardening model is chosen to simulate shear panel damper to determine the critical height to thickness ratio of shear panel dampers.

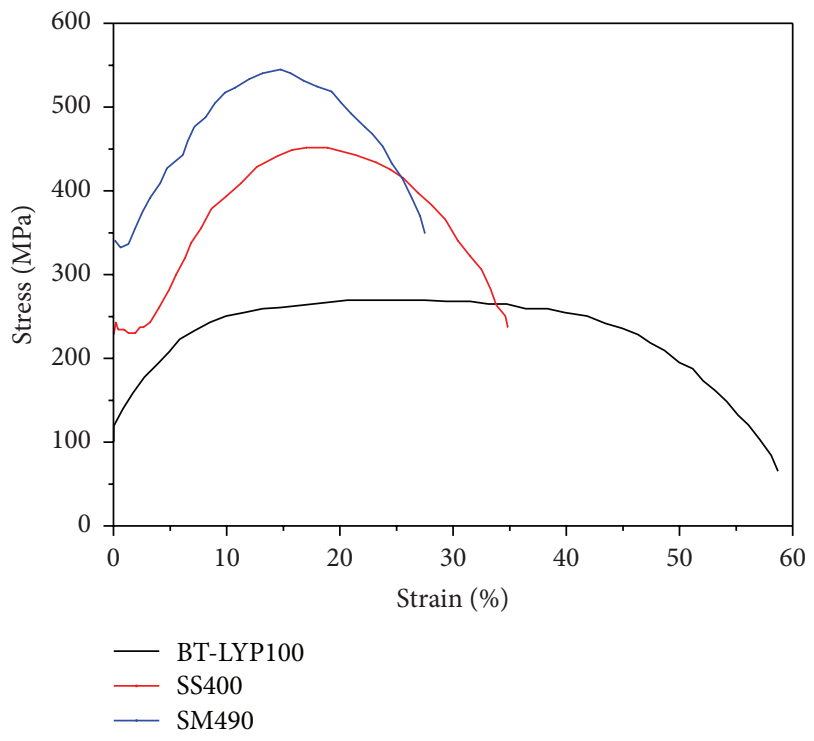

FIGURE 2: Comparison of stress-strain relationship between BLY100, SS400, and SM400.

\section{Test Research on Hysteretic Performance}

2.1. Components Size and Material Properties. The shear panel damper specimen consists of three parts: top and bottom flange plates, left and right flange plates, and coreboard, as shown in Figure 3. The top and bottom flange plates are $37 \mathrm{~mm}$ thick steel plates made of Q345, providing rigid constraints for the core-board and preventing torsion of damper, so that the stress state of core-board is more close to pure shear. Left and right flange plates are $12 \mathrm{~mm}$ thick steel plates made of Q345 that prevent the excessive out-ofplane buckling of core-board. The core-board is $15 \mathrm{~mm}$ thick 
TABLE 1: Mechanical properties of steel used in panels.

\begin{tabular}{lcccc}
\hline Steel grade & Yield point $(\mathrm{MPa})$ & Tensile strength $(\mathrm{MPa})$ & Elongation $(\%)$ & Elasticity modulus $(\mathrm{MPa})$ \\
\hline LYP100 & 102 & 247.4 & 55.41 & $2.04 \times 10^{5}$ \\
Q345 & 364.2 & 535.4 & 27.00 & $2.13 \times 10^{5}$ \\
\hline
\end{tabular}

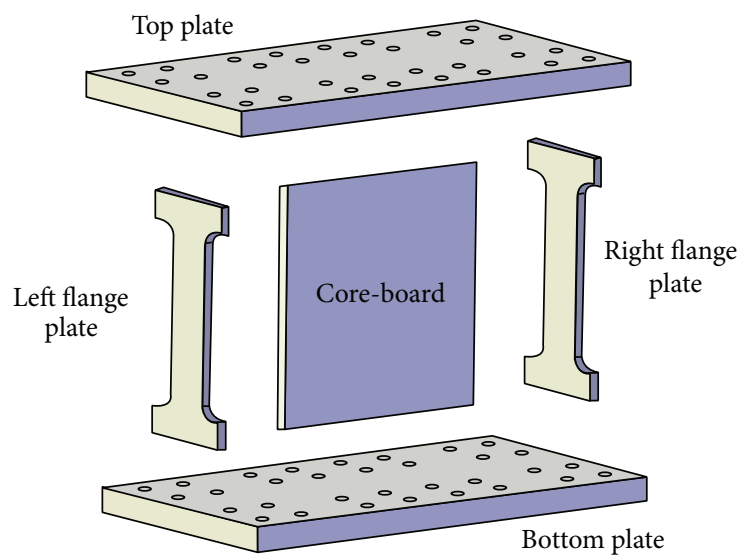

FIGURE 3: Model diagram of shear panel damper.
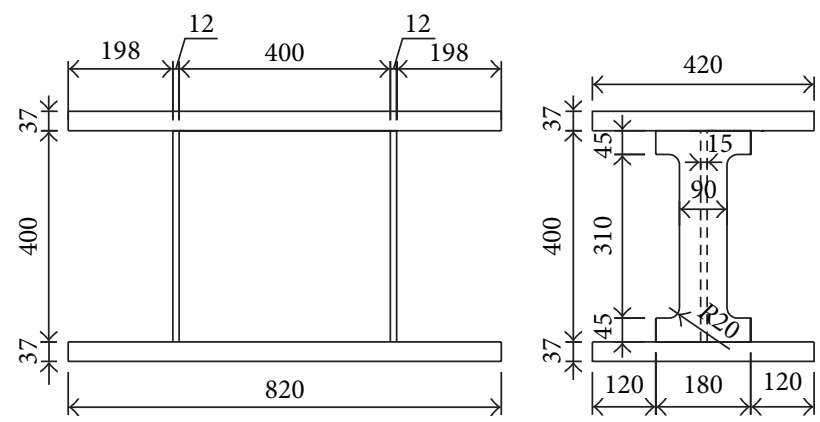

Figure 4: Detailed configuration of shear panel damper.

steel plate made of low-yield-point steel LYP100. The detailed dimension is illustrated in Figure 4.

In this paper, monotonic tensile tests were firstly conducted with the standard tensile specimen made of LYP100 and Q345. The properties of steels used in dampers are shown in Table 1.

2.2. Introduction of Experiment. The test is carried out on the reacting-force wall in the Structure and Seismic Experiment Center in School of Civil Engineering in Harbin Institute of Technology (HIT). In the test, articulated frame provides the constraints for dampers and hydraulic jack provides lateral force for the framework, as shown in Figure 5.

In the test, the displacement measurement mainly includes relative displacement of the top and bottom flange plates, out-of-plane buckling displacement of core-board, and lateral displacement of the articulated framework. Displacement is measured by the Linear Variable Differential
Transformer (LVDT). Figure 6 shows arrangement of displacement transducers. Two transducers, number 3 and number 4 , are arranged on the top flange plates to measure torsion of damper in the loading process. Along the diagonal of coreboard, number 5 , number 6 , and number 7 transducers are arranged to measure out-of-plane buckling of the core-board.

The loading history of hysteretic performance test consists of elastic stage and post-yielding stage. In the elastic stage, two cycles are performed for each force level under the $0.5 P_{y}$ and $0.75 P_{y}\left(P_{y}\right.$ is calculated by formula (1)). After that, the specimens are loaded cyclically according to the loading process in Figure 7 [12]. Here, $\gamma$ is defined as the horizontal displacement at the top of the specimen relative to bottom divided by the clear height of core-bored. There are 11 loading levels, with each level cycle being carried out twice. The loading is continued until the damper is damaged in the last level. The standard of damage is the bearing capacity of damper decrease by $10 \%$ or excessive out-of-plane buckling and cracks occurring in the core-board $[19,20]$.

2.3. Analysis of Experiment Result. By monotonic cyclic loading, the hysteretic curves of damper LP15CY, whose coreboard is $15 \mathrm{~mm}$ thick, are obtained and shown in Figure 8 . Normalized horizontal force $\left(P / P_{y}\right)$ versus shear angle $(\gamma)$ relationship is obtained according to the following formula and shown in Figure 9:

$$
P_{y}=A \cdot \frac{f_{y}}{\sqrt{3}} .
$$

Here, $A$ is the cross-sectional area of the core-board (not including left and right flange sections). $f_{y}$ is the yield stress of the core-board material; $f_{y}=102 \mathrm{MPa}$ in this experiment.

Skeleton curve and the equivalent viscous damping coefficient [21] are important parameters to study damper seismic response. Skeleton curve is connection of the peak point of each hysteretic loop. Equivalent viscous damping coefficient is shown in Figure 10, whose calculating formula is as follows:

$$
h_{e}=\frac{1}{2 \pi} \frac{S_{i}}{S_{\mathrm{OAB}}+S_{\mathrm{OCD}}} .
$$

Here, $S_{i}$ is the area of one cycle hysteretic loop. According to the conception of skeleton curve and equivalent viscous damping coefficient, we can get two curves, as shown in Figures 11 and 12.

The hysteretic curve of LP15CY is very full with no pinching phenomenon, which means good plastic deformation ability, and the peak bearing capacity reaches $1200 \mathrm{kN}$ meaning that the damper has high bearing capacity reserves. The skeleton curve shows a trend of rising without strength degradation phenomenon. The equivalent viscous damping 


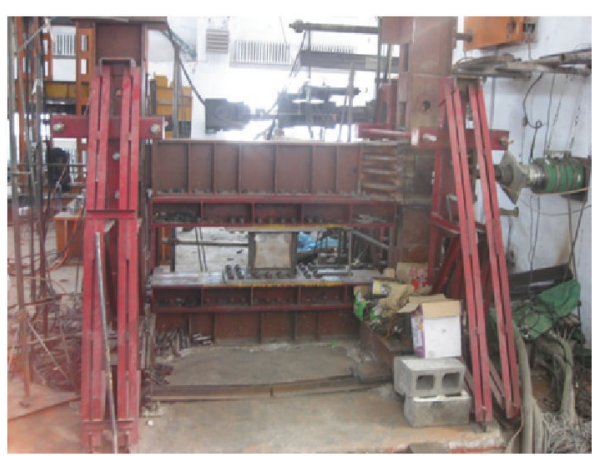

(a) Articulated frame

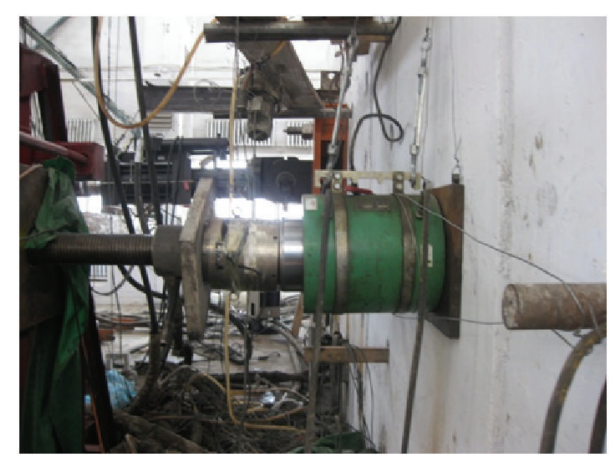

(b) Hydraulic jack

FIGURE 5: Loading device of experiment.
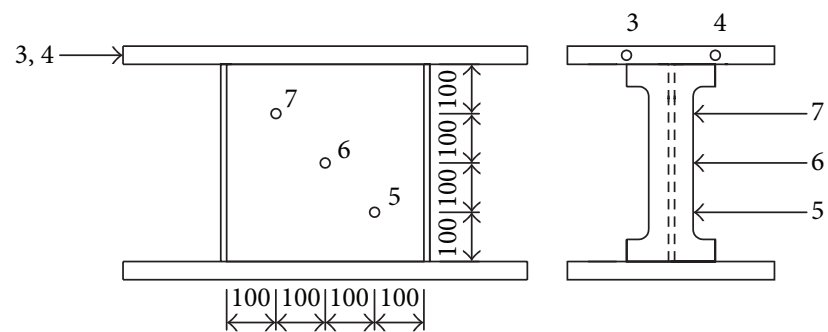

Figure 6: Arrangement of displacement transducers.

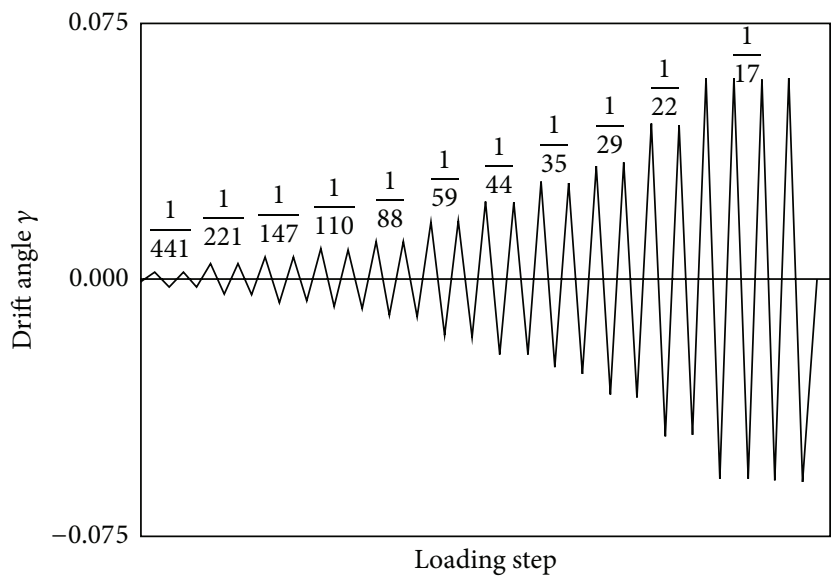

FIGURE 7: Loading process of dampers.

coefficient curve also shows a trend of rising in the process of loading, which suggests that the hysteretic curve is getting fuller and fuller and the energy dissipation performance is getting better and better with the increase of loading displacement. Hysteretic curve, skeleton curve, and equivalent viscous damping coefficient curve have the same trend, indicating that the $15 \mathrm{~mm}$ thick core-board damper has fine and stable performance. This damper is an ideal equipment of energy dissipation.

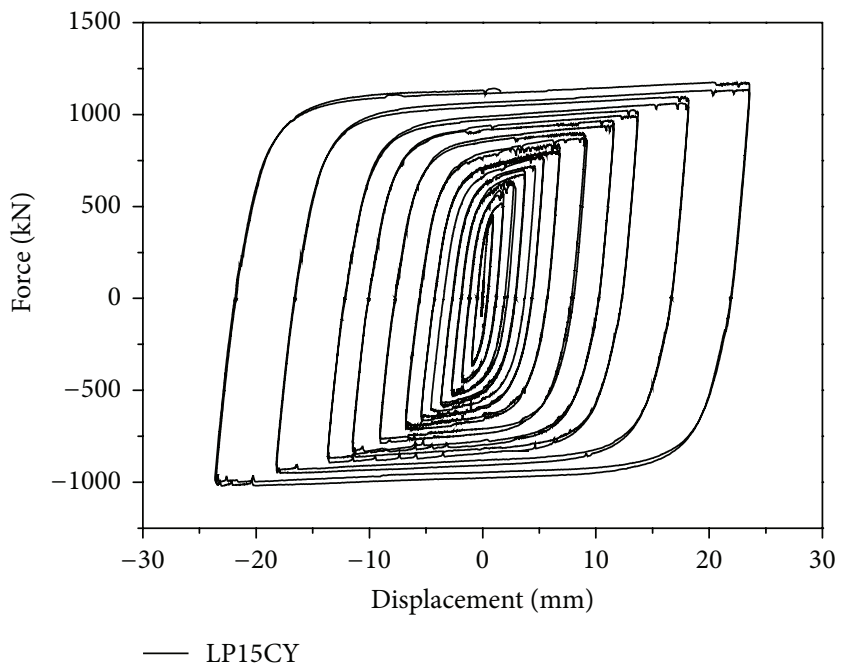

Figure 8: Hysteretic curves of damper.

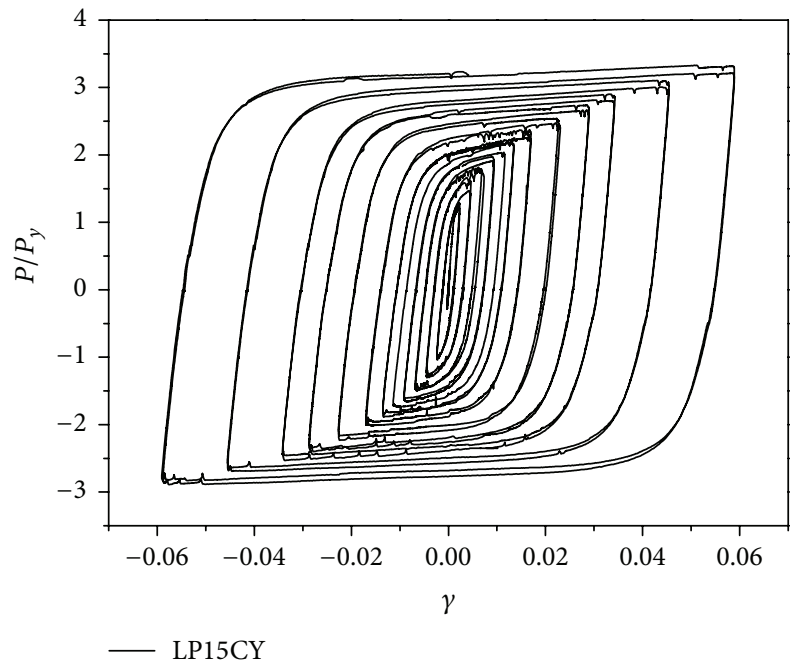

FIGURE 9: Nondimensional hysteretic curve. 


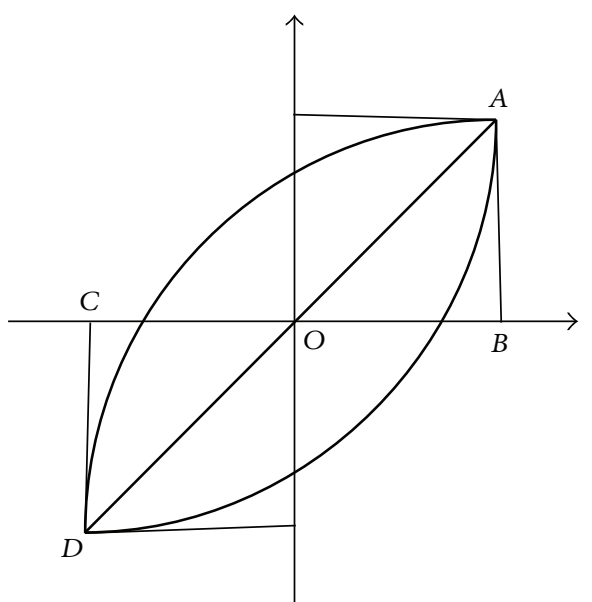

FIGURE 10: Calculating diagram of equivalent viscous damping coefficient.

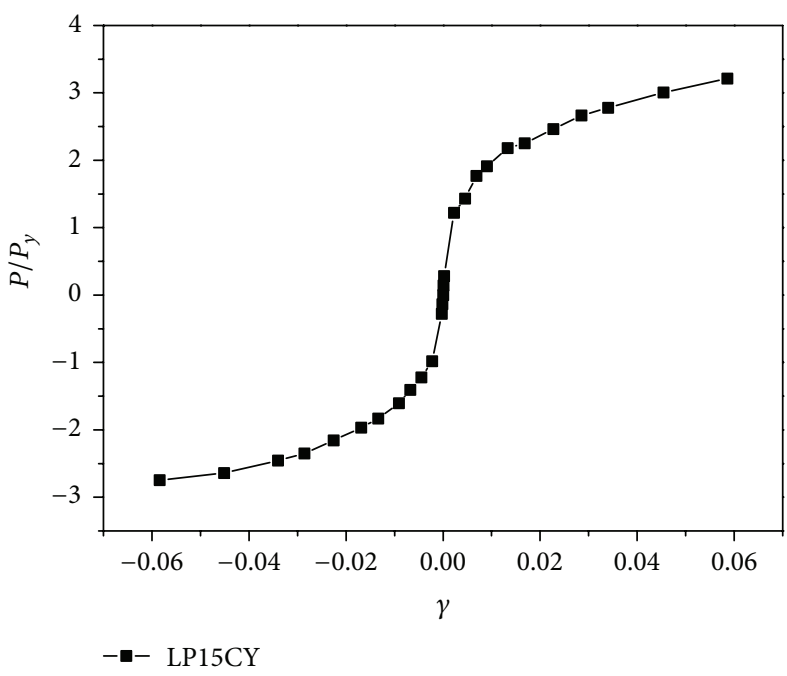

FIgURE 11: Nondimensional skeleton curve.

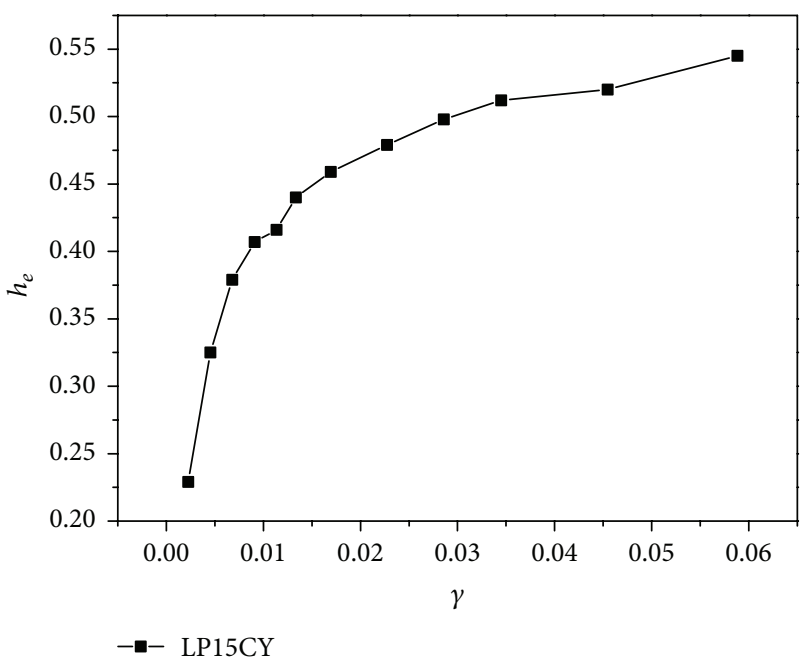

FigURE 12: Equivalent viscous damping coefficient.

\section{Finite Element Simulation}

The experiments can test various properties of dampers, but the price of tests is expensive and the tests are also with low efficiency. Hence more analyses are performed with finite element analysis software ABAQUS. Firstly, some simulation analyses have been performed to make contrast with test results to find out reasonable models. Then various parameters analyses are performed on the basis of existing models to obtain properties of dampers.

3.1. Finite Element Model. On the basis of experiment model, a 1:1 finite element model is built. In this model, top and bottom flange plates are built with discrete rigid body elements; left and right flange plates and core-board are built with shell elements, as shown in Figure 13.

3.2. Material Model. This paper uses the combined hardening model [22] to simulate the core-board and the isotropic hardening model [22] to simulate the flange plates. The constitutive models of materials are obtained from the monotonic tensile tests. The nominal stress-strain curves obtained from tests are translated into the true stress-strain curves. The constitutive models of low-yield-point steel used in coreboard and Q345 steel used in flange plates are presented in Figures 14 and 15.

3.3. Analysis of Finite Element Simulation Results. On the basis of experiment loading history, the simulation analysis of hysteretic test is performed and then simulation hysteretic curves are obtained. According to the method used before, normalized force and displacement curves are shown in Figure 16. Figure 17 shows the comparison of test result and simulation result. Then the skeleton curve and equivalent viscous damping coefficient curve and comparison with test results are obtained and shown in Figures 18 and 19, respectively.

Through the analyses above, hysteretic curve, skeleton curve, and equivalent viscous damping coefficient curve of simulation results matched well with experiment results. From hysteretic and skeleton curves, when it comes to the positive loading, the peak value of each loop basically coincided with test result. Under the reverse loading, the peak value of each loop in simulation result is greater than the test result, but they have the same trend and no strength degradation phenomenon occurs. From the equivalent viscous damping coefficient curves, the trends of simulation result and test result are the same in general, both rising gradually. The increasing rate of test result is greater than simulation result. When it comes to the ninth level loading in simulation, the curve becomes horizontal, but the test curve keeps increasing through the whole loading history with no horizontal section. It is related to the unobvious cyclic hardening phenomenon in simulation. In conclusion, the finite element model can present the actual property of damper. So the model can be used for qualitative analysis of this kind of damper. 
TABLE 2: Basic parameter used in simulation.

\begin{tabular}{lcccc}
\hline Specimen number & Core-board material & Flange plates material & Core-board thickness (mm) & Height to thickness ratio \\
\hline LP-1 & LYP100 & Q345 & 8.89 & 45 \\
LP-2 & LYP100 & Q345 & 10 & 40 \\
LP-3 & LYP100 & Q345 & 11.43 & 35 \\
LP-4 & LYP100 & Q345 & 13.33 & 30 \\
\hline
\end{tabular}

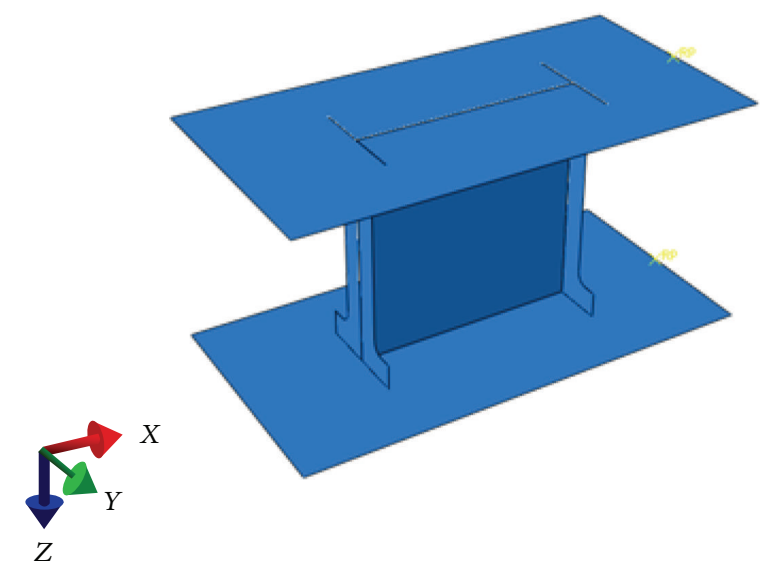

(a) Geometric model

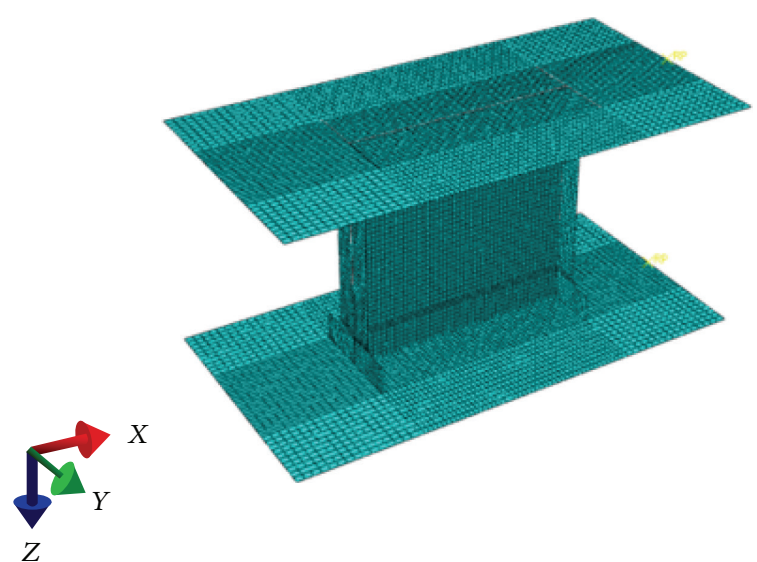

(b) Finite element model

FIGURE 13: Model of shear panel dampers.

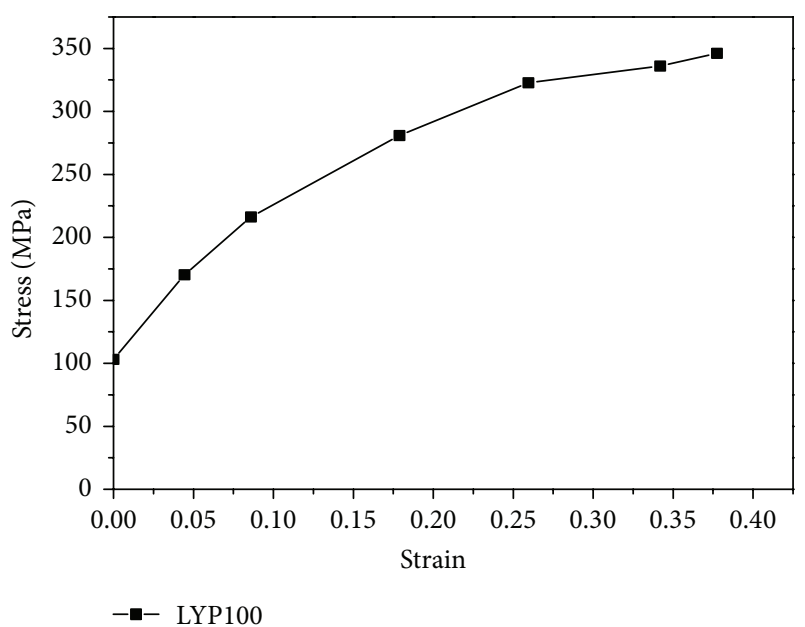

FIGURE 14: True stress-strain curve of LYP100.

3.4. Height to Thickness Ratio. Height to thickness ratio $[23,24]$ is defined as the ratio value between height and thickness of core-board. It is an important parameter in designing dampers. When designing a damper, the property of damper should be given priority and then comes the economic factor. So the ideal dampers should meet both the property and the economic requirements. Finding the critical height to thickness ratio of core-board is very important. With the height to thickness ratio as variable, simulation

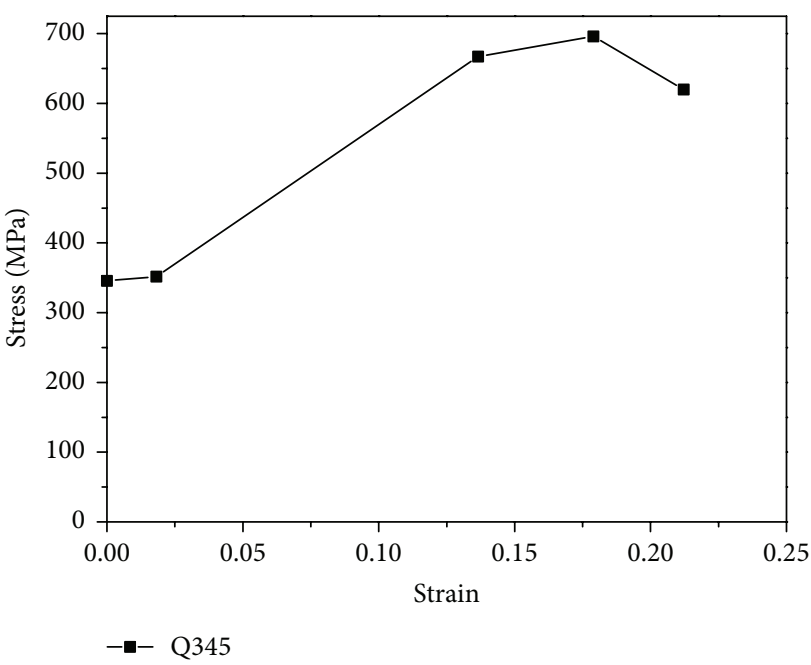

FIGURE 15: True stress-strain curve of Q345.

analyses are performed with the model introduced before. Basic parameters of simulation are shown in Table 2.

Through the simulation, four normalized hysteretic curves with different height to thickness ratios are obtained and shown in Figure 20. According to the method put forward before, the skeleton and equivalent viscous damping coefficient curves obtained from hysteretic curves and the comparison of four curves are shown in Figures 21 and 22, respectively. 


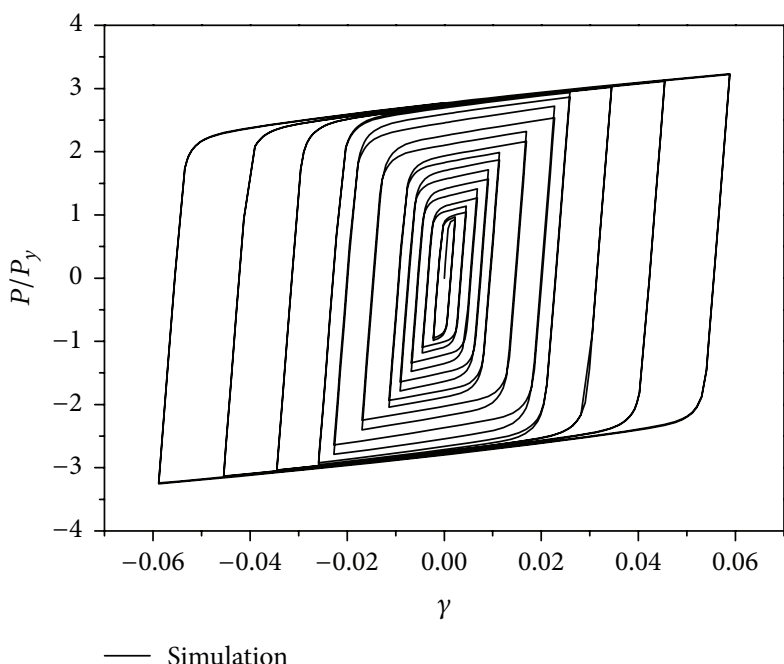

FIGURE 16: Hysteretic curve of simulation result.

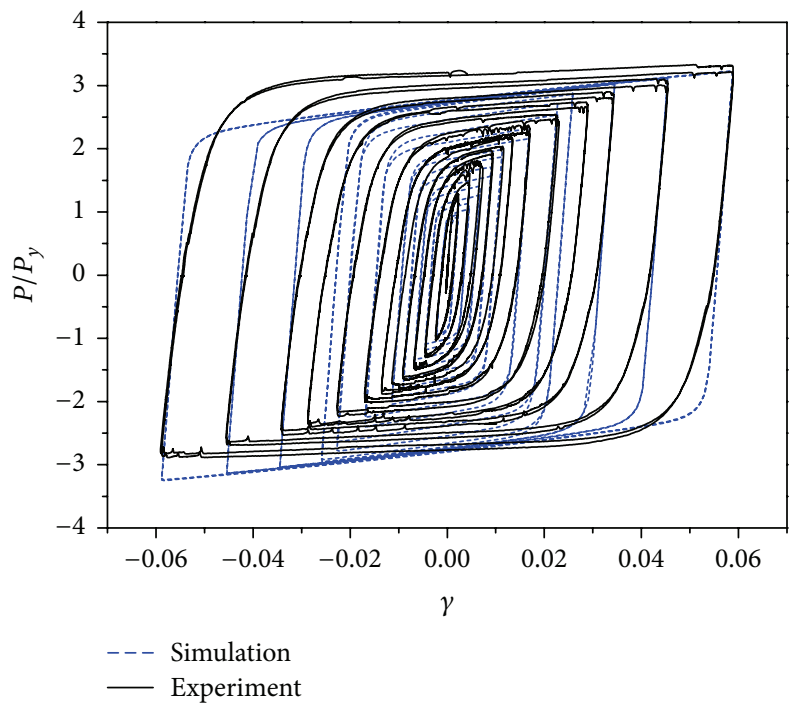

FIgURE 17: Comparison of simulation and experiment results.

Through the analysis of hysteretic curves, skeleton curves, and equivalent viscous damping coefficient curves, with the decrease of height to thickness ratio, the hysteretic curves become more and more satiating. The hysteretic curves of LP-1, LP-2, and LP-3 are all having pinching phenomenon; the curve of LP-4 shows no pinching. From the skeleton and equivalent viscous damping coefficient curves, LP-1, LP2 , and LP-3 all have decreasing trend after several loading steps, but LP-4 has no decreasing stage with a stable energy dissipation performance. It can be concluded that the critical height to thickness ratio of core-board is in the range of 30 and 35 .

\section{Experimental Study on Fatigue Property}

4.1. Size of Specimens and Loading System. Fatigue property is an important factor in the design of shear panel dampers.

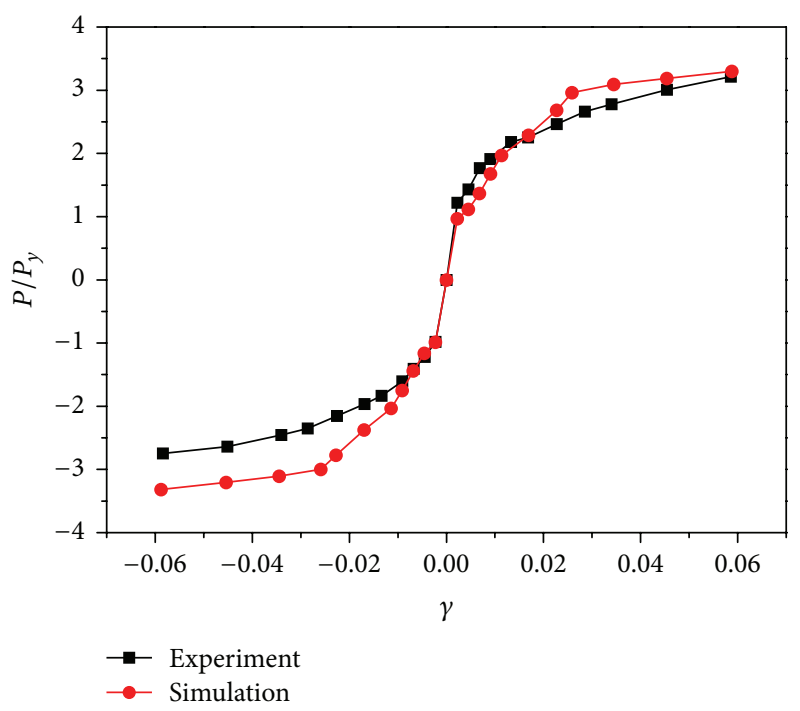

FIGURE 18: Comparison of skeleton curves.

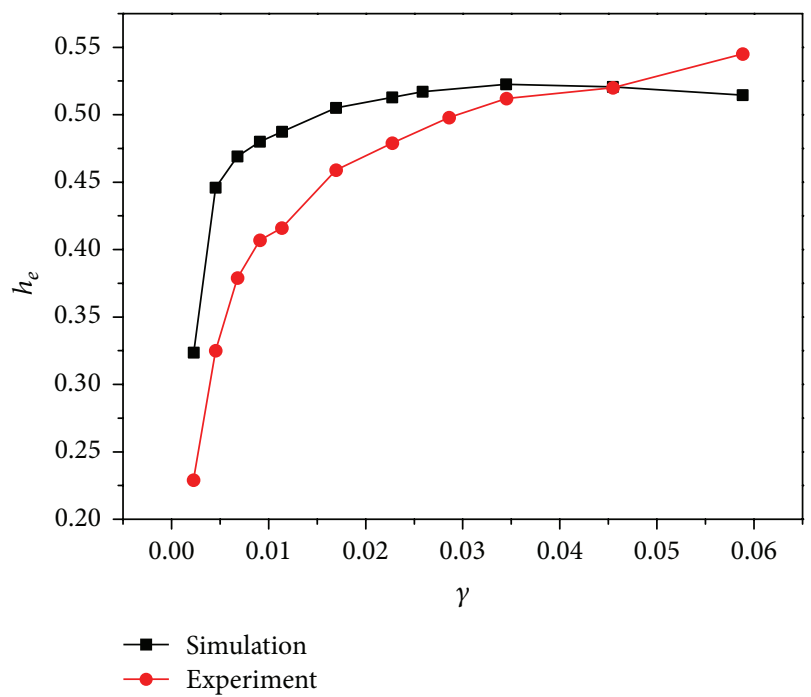

FIGURE 19: Comparison of equivalent viscous damping coefficient curves.

An ideal damper should not only have good energy dissipation performance, but also have well fatigue property. This paper presents experiments on three nonstiffener shear panel dampers with $15 \mathrm{~mm}$ thick core-board made of low-yieldpoint steel. The tests are with constant amplitude cyclic load to investigate the relationship between fatigue performance and the size of amplitude. The sizes of specimens used in the fatigue tests are the same as those in the hysteretic test. The serial number, basic parameters of specimens, and loading methods of experiments are shown in Table 3.

4.2. Result Analysis of Fatigue Experiments. The three dampers are tested under constant amplitude loading with the amplitude of $20 \mathrm{~mm}, 45 \mathrm{~mm}$, and $60 \mathrm{~mm}$, respectively. Then normalized hysteretic curves under different amplitudes are obtained and shown in Figures 23-25. According 
TABLE 3: Basic parameter of fatigue experiment.

\begin{tabular}{lcccc}
\hline Specimen number & Core-board material & Flange plates material & Core-board thickness (mm) & Loading amplitude (mm) \\
\hline LP-1F & LYP100 & Q345 & 15 & 20 \\
LP-2F & LYP100 & Q345 & 15 & 45 \\
LP-3F & LYP100 & Q345 & 15 & 60
\end{tabular}

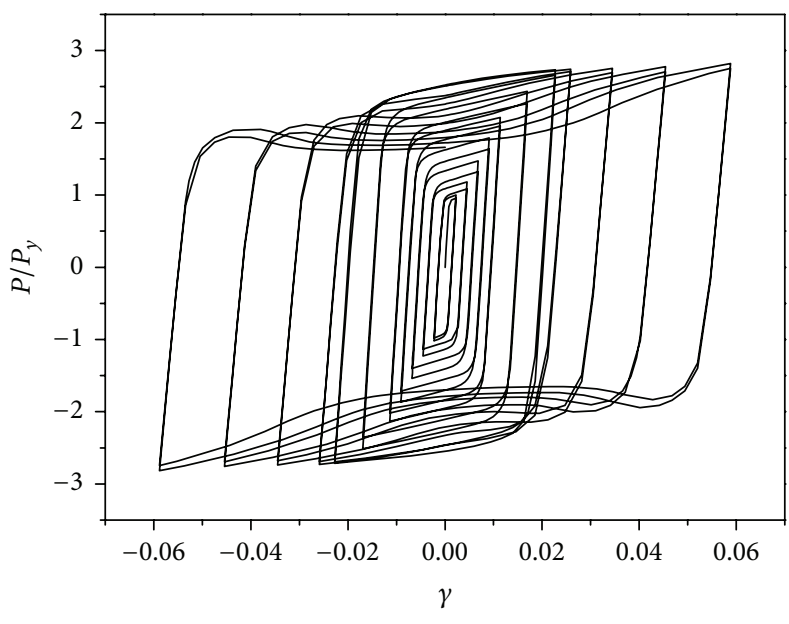

- LP-1

(a) LP-1

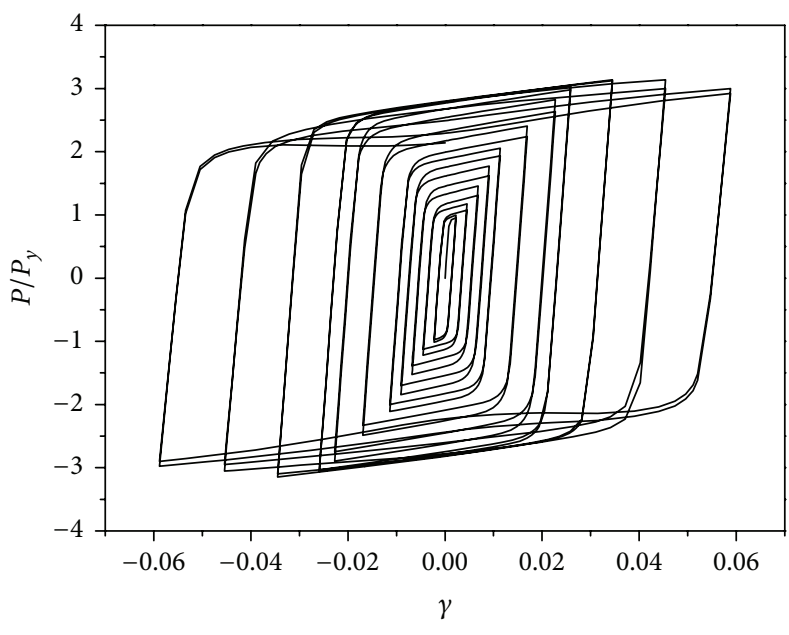

- LP-3

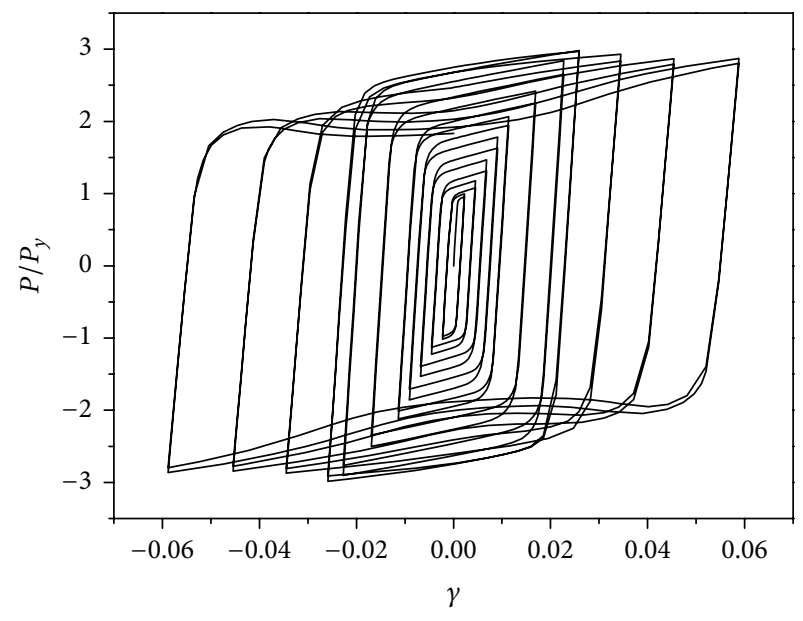

- LP-2

(b) LP-2

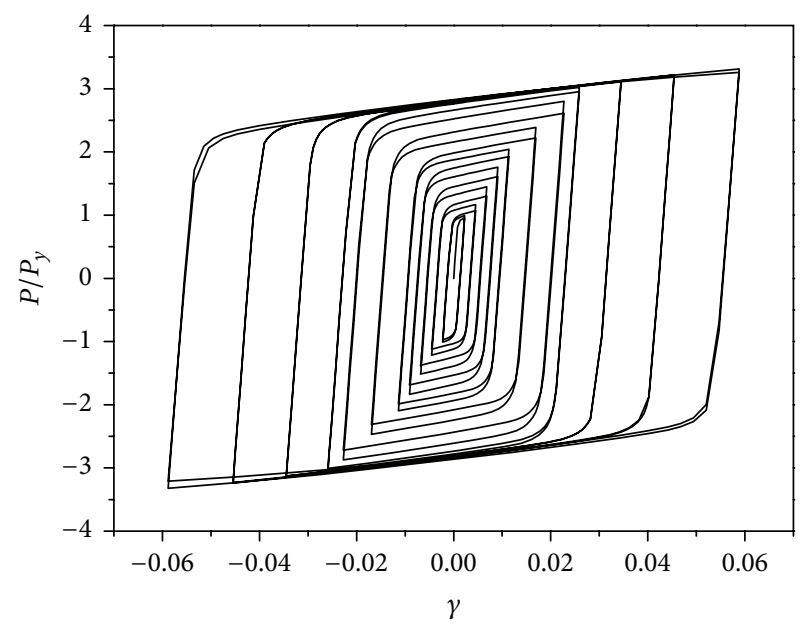

(d) LP-4

(c) LP-3

FIGURE 20: Nondimensional hysteretic curves of four conditions.

to the force-displacement hysteretic curve, every lap of energy dissipation for each damper under the corresponding amplitude is figured out, and the comparison between them is shown in Figure 26. Figure 27 shows the contrast of accumulated energy dissipation versus cyclic number about three dampers in different working conditions. The accumulated energy dissipation curves are the sum of every lap of energy dissipation. In the elastic stage of loading history, the test is conducted under two different force levels in order to
TABLE 4: Initial elastic stiffness.

\begin{tabular}{lccc}
\hline Specimen number & LP-1F & LP-2F & LP-3F \\
\hline Initial elastic stiffness $(\mathrm{kN} / \mathrm{mm})$ & 794.165 & 743.857 & 749.016 \\
\hline
\end{tabular}

measure the initial elastic stiffness of specimen. According to the test results, the initial elastic stiffness of specimen is fitted as shown in Table 4 . Figure 28 presents the fitting initial elastic stiffness curves of specimen. 


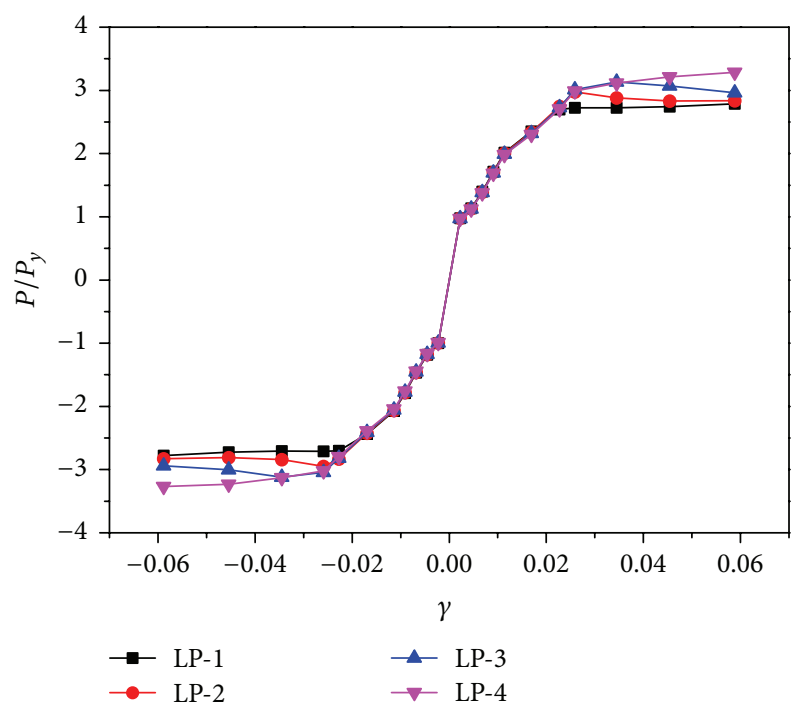

FIGURE 21: Comparison of skeleton curves.

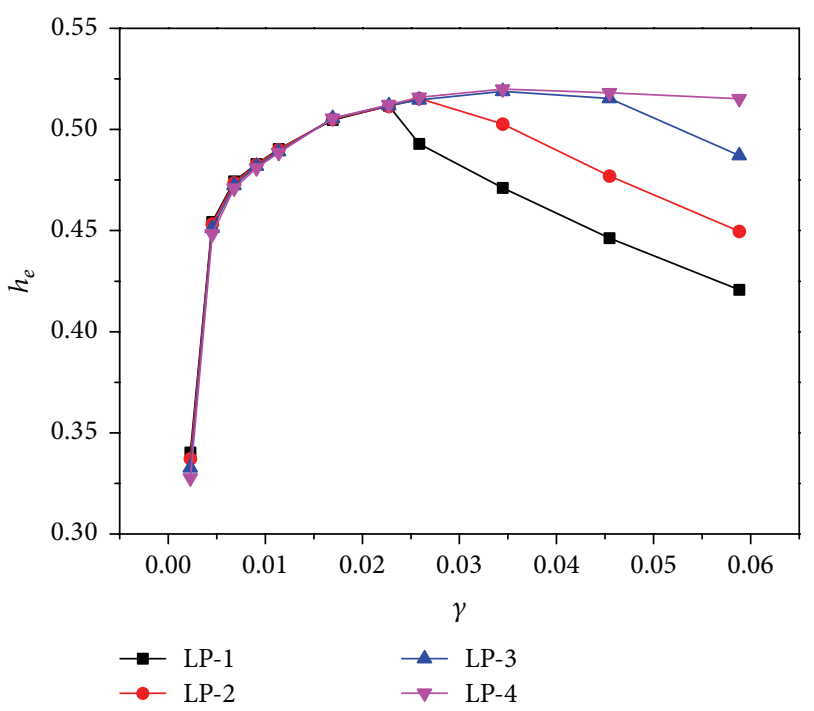

FIGURE 22: Comparison of equivalent viscous damping coefficient curves.

Having cyclic loading with the amplitude of $20 \mathrm{~mm}$, the hysteretic curves remain stable before 28 cycles. The hysteretic loops are full, with no pinching phenomenon, and the lap energy dissipation curves stay horizontal. The damper is with stable energy dissipation performance. After 28 cycles, the hysteretic loops start pinching. With the increase of cycles, the pinching phenomenon becomes more and more obvious; the distortion occurs and aggravates gradually. The lap energy dissipation curve shows a trend of decrease. Energy dissipation performance of the damper begins to degenerate. When it comes to 46 cycles, cracks appear in the middle of core-board and the weld joint is failure between flange plates and core-board. The failures are shown in Figure 29.

Having cyclic loading with the amplitude of $45 \mathrm{~mm}$, the hysteretic curves stay stable before 9 cycles. The hysteretic

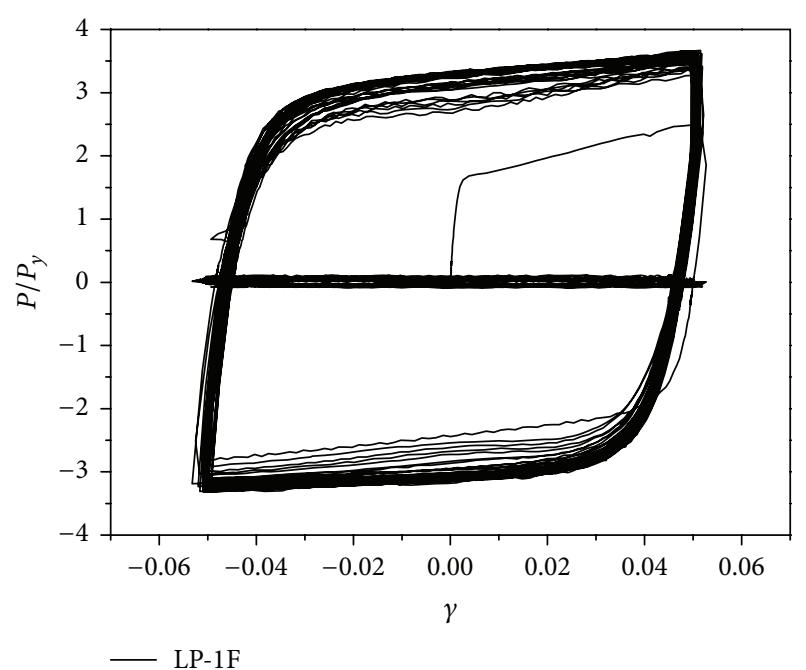

FIGURE 23: Nondimensional hysteretic curves of $20 \mathrm{~mm}$ amplitude.

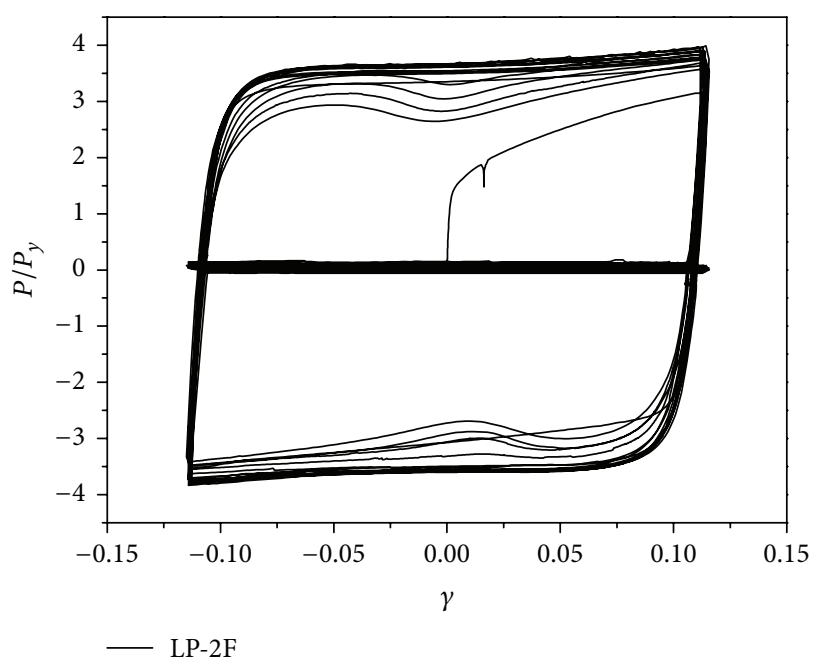

FIgURE 24: Nondimensional hysteretic curves of $45 \mathrm{~mm}$ amplitude.

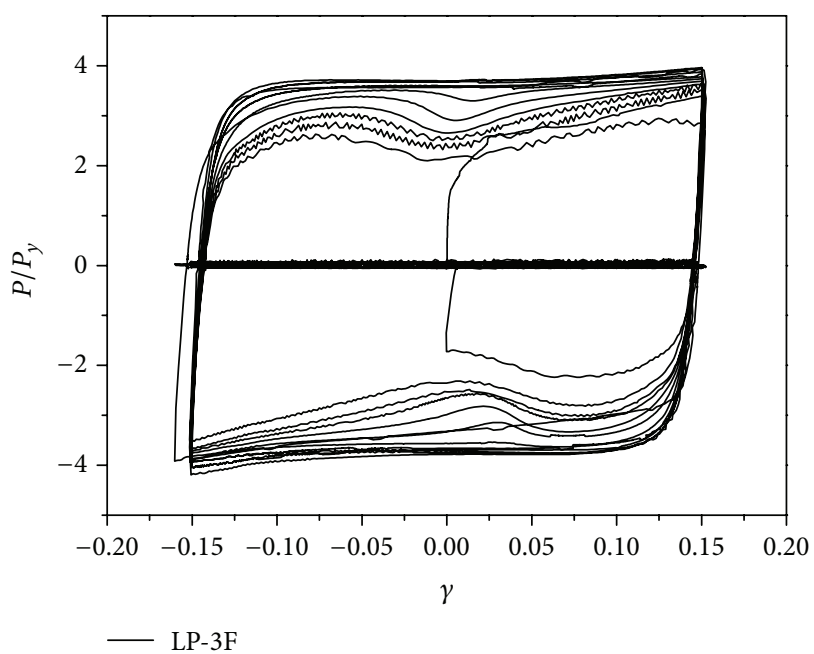

FIGURE 25: Nondimensional hysteretic curves of $60 \mathrm{~mm}$ amplitude. 


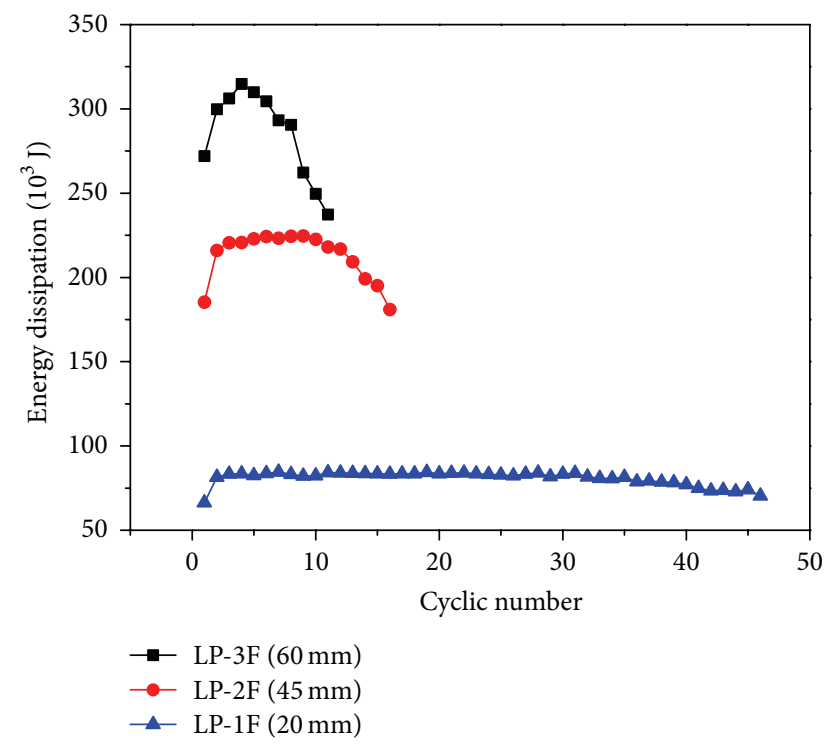

FIGURE 26: Every lap of energy dissipation curves of dampers in three kinds of amplitude.

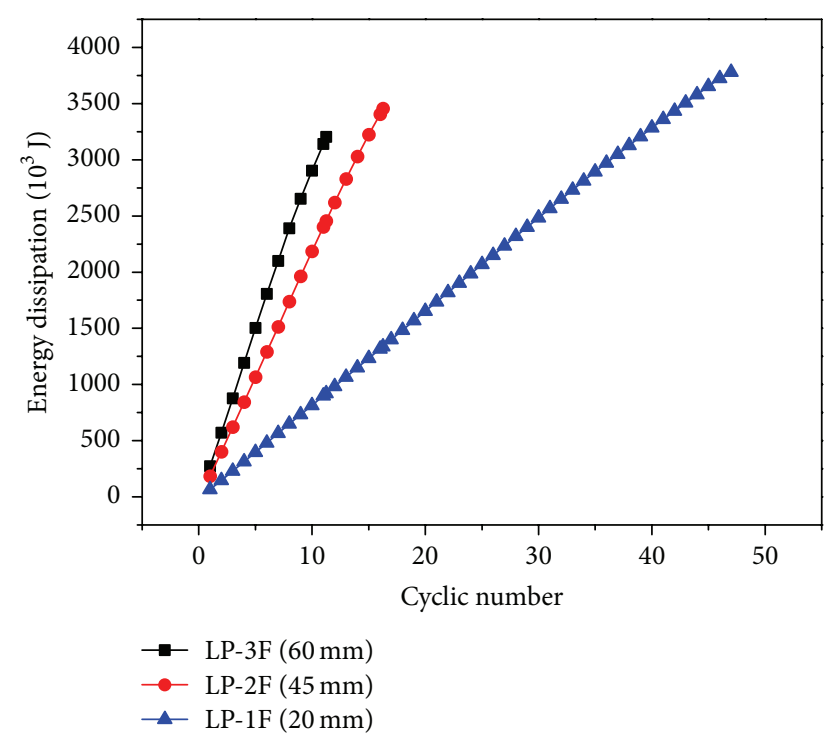

FIGURE 27: Accumulated energy dissipation curves of dampers in three kinds of amplitude.

loops are full, with no pinching, and the lap energy dissipation curves keep horizontal. The damper is with stable energy dissipation performance. After 9 cycles, the hysteretic loops start pinching and the distortion occurs in the core-board; with the increasing of cycles, the pinching and distortion are increasingly severe. Lap energy dissipation curve begins to decrease, and the decrease speed is faster than the test under the amplitude of $20 \mathrm{~mm}$. Energy dissipation of the damper is starting to degenerate. When it comes to 16 cycles, the damper becomes failure. The failure is similar to the test with amplitude of $20 \mathrm{~mm}$, as shown in Figure 30.
Having cyclic loading with the amplitude of $60 \mathrm{~mm}$, the hysteretic curves hold steady before 4 cycles. The hysteretic loops are full, with no pinching, and the lap energy curve is increasing with the cycle numbers. The damper has fine energy dissipation property. After 4 cycles, the distortion and pinching in core-board appear and are more severe than the other two dampers analyzed before. When it comes to 11 cycles, the damper becomes failure. Figure 31 shows the failure mode of the damper; the cracks in the core-board are more evident than the other two tests and it shows greater lateral buckling.

According to all the analyses above, the shear panel dampers with $15 \mathrm{~mm}$ thick core-board present fine fatigue capacity under small amplitude cyclic loading. With the increase of amplitude, the fatigue performance of dampers is getting worse and worse. From the accumulated energy dissipation curves, no matter what the amplitude size is, all the energies dissipated by the dampers are approaching each other. The initial elastic stiffness fitting curves show that the initial elastic stiffness is relatively large, indicating that the damper increases the structure total stiffness to some extent.

\section{Conclusion}

This paper has made an in-depth investigation of the nonstiffener shear panel made of low-yield-point steel. According to hysteretic experiment, finite element simulation, and fatigue performance tests, the major findings of this study can be briefly generalized as follows:

(1) Nonstiffener shear panel damper with $15 \mathrm{~mm}$ thick core-board made of low-yield-point steel has a good hysteretic property. Under the cyclic loading with small amplitude, the property of the shear panel damper is stable, and the damper performs a fine fatigue property. This type of damper is an ideal energy consumption equipment.

(2) It can be found that the critical height to thickness ratio of this type of nonstiffener shear panel damper is between 30 and 35 by using the finite element simulation. The range of the height to thickness ratio can be a reference of the damper design.

(3) According to the constant amplitude cyclic loading test, failure modes of the three dampers are similar to each other. They all have the presentations as follows: cracks appearing in the middle of core-board, break of the weld joint between flange plates and corebored, and major lateral buckling in the core-board. The deformation of core-board is not only in shear but also in distortion of plate. In the subsequent design, reducing the lateral buckling, distortion of plate, and the influence of weld joint should be taken into consideration.

(4) From the every lap energy dissipation and accumulated energy dissipation curves, it can be concluded that this type of damper has a stable energy dissipation capacity and can dissipate large amounts of 


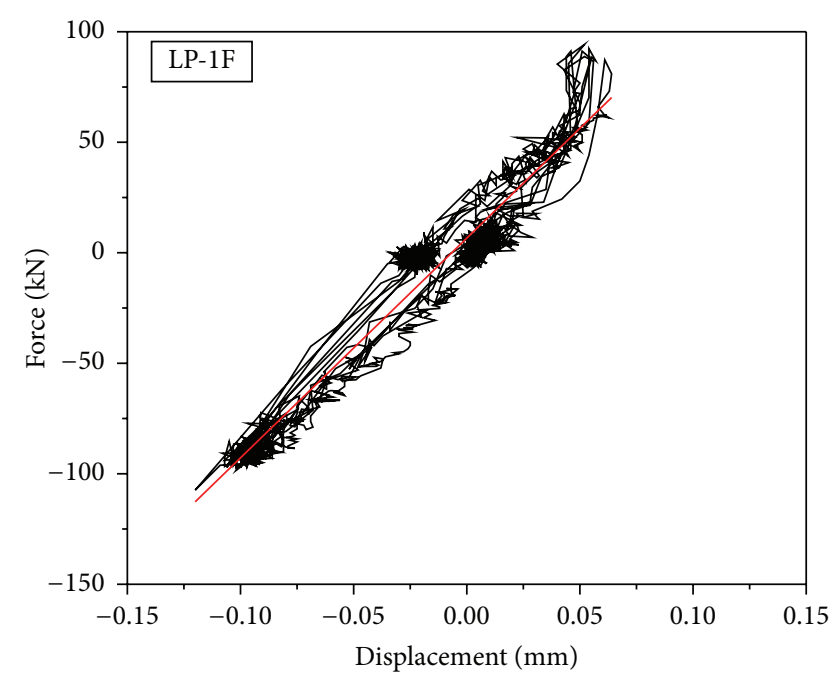

(a) Initial elastic stiffness fitting curves of $20 \mathrm{~mm}$ amplitude

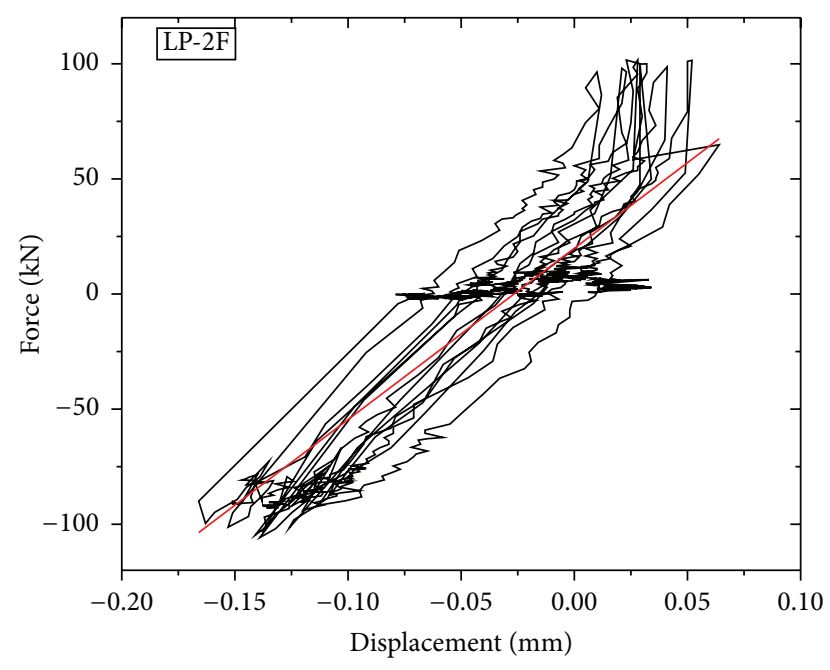

(b) Initial elastic stiffness fitting curves of $45 \mathrm{~mm}$ amplitude

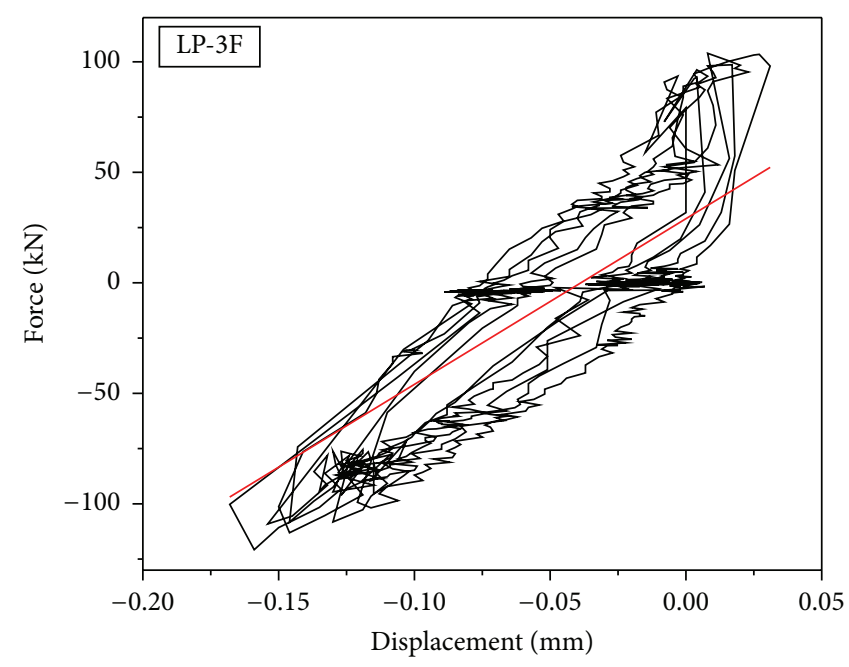

(c) Initial elastic stiffness fitting curves of $60 \mathrm{~mm}$ amplitude

FIgURE 28: Initial elastic stiffness fitting curves.

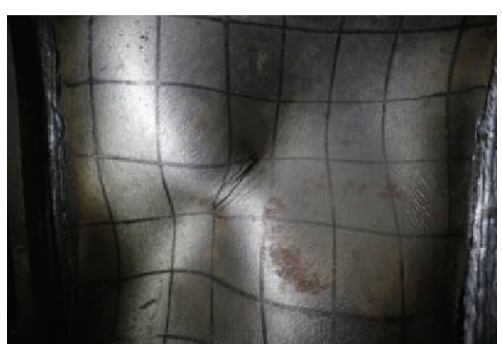

(a) Cracks of core-board

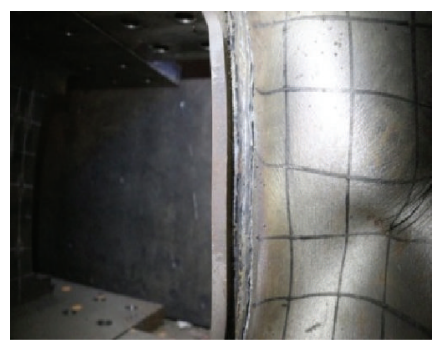

(b) Weld failure

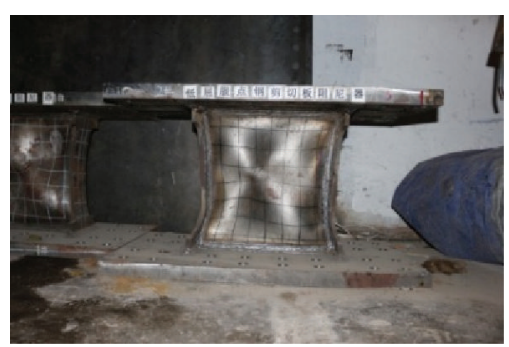

(c) Global deformation

FIGURE 29: Fatigue failure type of damper in $20 \mathrm{~mm}$ amplitude. 


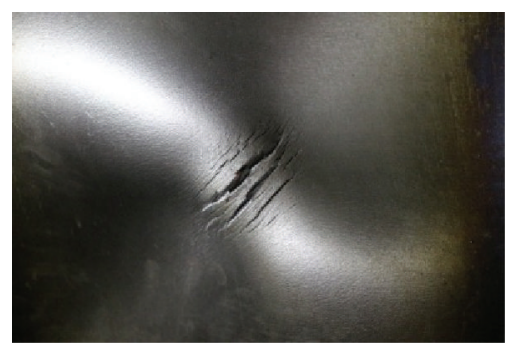

(a) Cracks of core-board

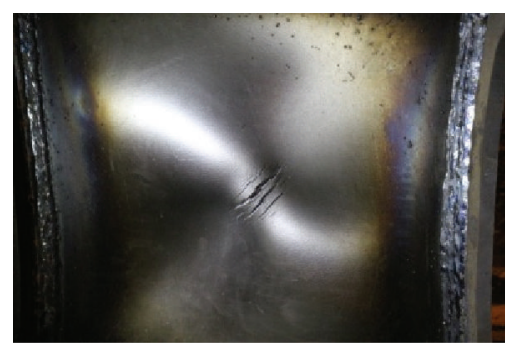

(b) Weld failure

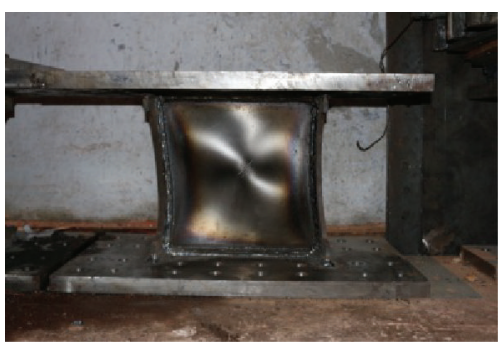

(c) Global deformation

FIGURE 30: Fatigue failure type of damper in $45 \mathrm{~mm}$ amplitude.

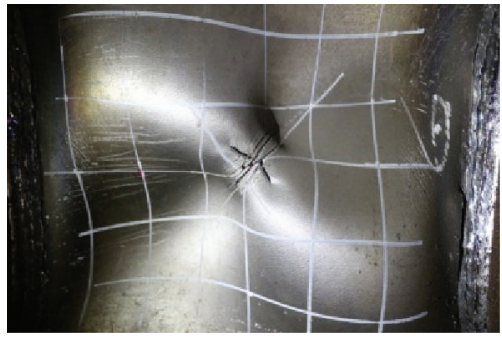

(a) Cracks of core-board

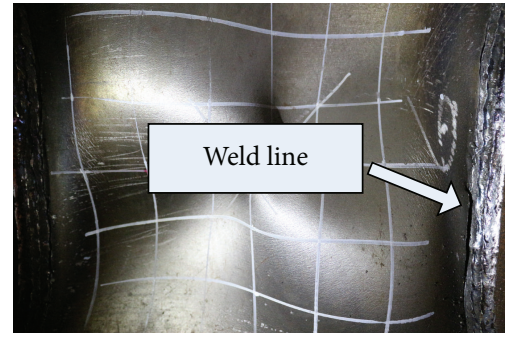

(b) Weld failure

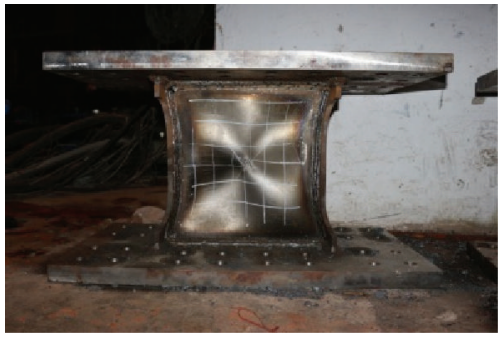

(c) Global deformation

FIgURE 31: Fatigue failure type of damper in $60 \mathrm{~mm}$ amplitude.

energy. Under cyclic loading with the amplitude of $20 \mathrm{~mm}$, the hysteretic curves remain stable before 28 cycles and the hysteretic loops are full, indicating that the damper can function effectively for the smaller vibration. It can be a fine energy dissipation device of structural vibration control.

\section{Disclaimer}

The results, opinions, and conclusion expressed in the paper are all on behalf of the authors.

\section{Conflict of Interests}

The authors declare that there is no conflict of interests regarding the publication of this paper.

\section{Acknowledgments}

The work presented herein is part of a study in progress at Harbin Institute of Technology (HIT) under Grant no. 51478156 from the National Science Foundation of China (General Program), Grant no. E2015018 from the National Science Foundation of Heilongjiang, China (General Program), and Grant no. 51078118 from the National Science Foundation of China (General Program). Ji-long Li as the NSFC Program Director thanks the members of the program, Ya-nan Tang, Xuan-ming Liu, and so forth, for their test researches and simulation analyses.

\section{References}

[1] O. Jin-ping, Structural Vibration Control-Active, Semi-Active and Intelligent Control, Science Press, 2003 (Chinese).

[2] T. Kobori and R. Minai, "Analytical study on active seismic response control," Transactions of the Architectural Institute of Japan, vol. 66, 1960.

[3] J. T. P. Yao, "Concept of structural control," ASCE Journal of Structure Division, vol. 98, no. 7, pp. 1567-1574, 1972.

[4] J. P. Ou, B. Wu, and T. T. Soong, "Recent advances in research on and application of passive energy dissipation systems," Earthquake Engineering and Engineering Vibration, vol. 16, no. 3, pp. 72-96, 1996.

[5] T. T. Soong and G. F. Dargush, Passive Energy Dissipation Systems in Structural Engineering, John Wiley \& Sons, London, UK, 1997.

[6] J. M. Kelly, R. I. Skinner, and A. J. Heine, "Mechanisms of energy absorption in special devices for use in earthquake resistant structures," Bulletin of the New Zealand Society for Earthquake Engineering, vol. 5, no. 3, pp. 63-88, 1972.

[7] Z.-Y. Chen, H.-B. Ge, T. Usami, and Y. Yuan, "Ultimate shear strength of shear panel damper under cyclic load," Journal of Shenyang University of Technology, vol. 33, no. 2, pp. 219-225, 2011 (Chinese).

[8] M. Nakashima, S. Iwai, M. Iwata et al., "Energy dissipation behaviour of shear panels made of low yield steel," Earthquake Engineering \& Structural Dynamics, vol. 23, no. 12, pp. 12991313, 1994.

[9] K. Otani, "Recent trend of technology for steel plates used in building construction," Nippon Steel Technical Report, vol. 54, pp. 27-36, 1992. 
[10] M. Aohashi, H. Mochizuki, T. Yamaguchi et al., "Development of new steel plates for building structural use," Steel Research, no. 334, pp. 17-28, 1989.

[11] T. Yamaguchi, T. Takeuchi, T. Nagao et al., "Seismic control devices using low-yield-point steel," Nippon Steel Technical Report, no. 77, pp. 65-72, 1998.

[12] M. Nakashima, "Strain-hardening behavior of shear panels made of low-yield steel. I: test," Journal of Structural Engineering, vol. 121, no. 12, pp. 1742-1749, 1995.

[13] H. Tamai, H. Takenaka, T. Nakano, O. Kojima, K. Kondoh, and M. Hanai, "On hysteretic damper using low-yield stress steel plate installed in K-braced frame," in Proceedings of the Annual Meeting of Architectural Institute of Japan, pp. 1447-1450, Tokyo, Japan, September 1991 (Japanese).

[14] M. Izumi, N. Kani, H. Narihara, Y. Kawamata, K. Ogura, and O. Hosozawa, "Low cycle fatigue test on shear yielding type lowyield stress steel hysteretic damper for response control, part 1 and 2," in Proceedings of the Annual Meeting of the Architectural Institute of Japan, pp. 1333-1336, Tokyo, Japan, 1992 (Japanese).

[15] L. Fu, Y.-Q. Zhang, Y.-R. Luo, Q. Yu, M.-T. Li, and X.-G. Zeng, "Low cycle fatigue properties of steel BLY160 with low yield point for damper," Journal of Iron and Steel Research, vol. 27, no. 3, pp. 65-69, 2015.

[16] S. Fengming, W. Donghui, L. Zigang, and B. Mingzhuo, "Application and development of low yield point steel," Material \& Heat Treatment, vol. 37, no. 6, pp. 85-89, 2008 (Chinese).

[17] S. Gong, G. Sheng, D. Yao, S. Li, and Q. Chen, "Research on steels for earthquake damping device," Iron and Steel, vol. 36, no. 9, pp. 55-57, 2001.

[18] D. Wen, F. Song, Z. Li et al., "Develop and performance study on low yield point steel used in earthquake control building," (Chinese), http://www.chinabaike.com/z/yj/554590.html.

[19] S. Zhongshuang, Research on behaviors of energy dissipation of shear panels dampers made of low-yield steel [M.S. thesis], Harbin Institute of Technology, Harbin, China, 2013.

[20] Z. Song, H. Li, L. Han et al., "Experimental study on hysteretic behavior of shear panel dampers made of steel with low yield point," Journal of Disaster Prevention and Mitigation Engineering, vol. 34, no. 3, pp. 289-295, 2014.

[21] W. Bin, Testing, analysis and design approaches of hysteretic energy dissipation systems [Ph.D. thesis], Harbin University of Civil Engineering and Architecture, 1998 (Chinese).

[22] H.-F. Chen, Elasticity and Plasticity, China Architecture \& Building Press, Beijing, China, 2004, (Chinese).

[23] S.-J. Chen and C. Jhang, "Cyclic behavior of low yield point steel shear walls," Thin-Walled Structures, vol. 44, no. 7, pp. 730-738, 2006.

[24] C. Zhang, Z. Zhang, and J. Shi, "Development of high deformation capacity low yield strength steel shear panel damper," Journal of Constructional Steel Research, vol. 75, pp. 116-130, 2012. 

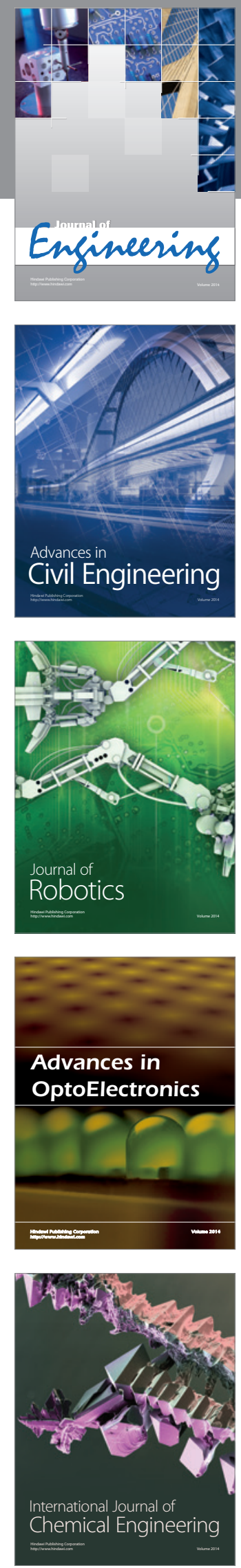

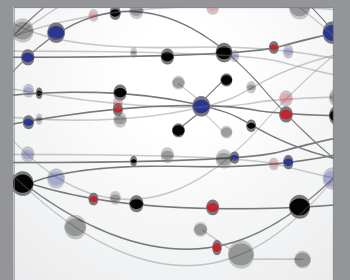

The Scientific World Journal
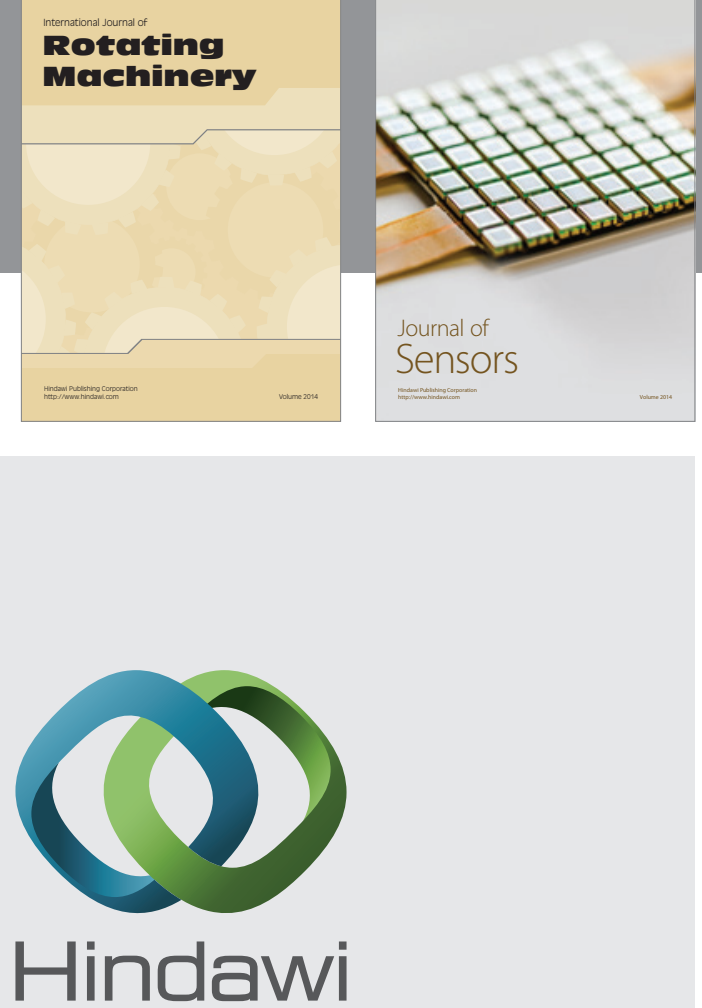

Submit your manuscripts at http://www.hindawi.com
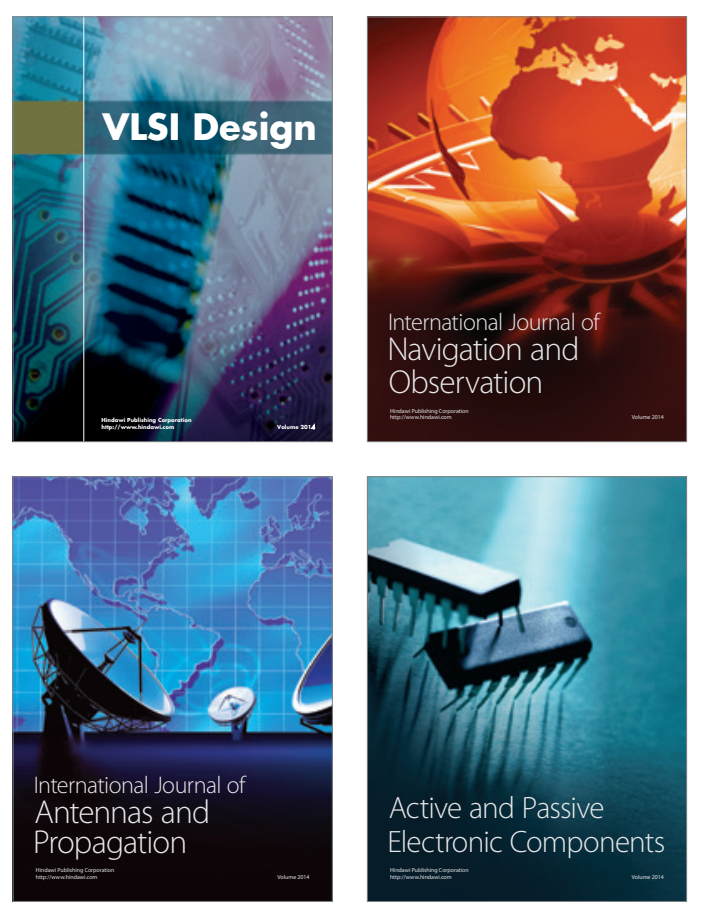
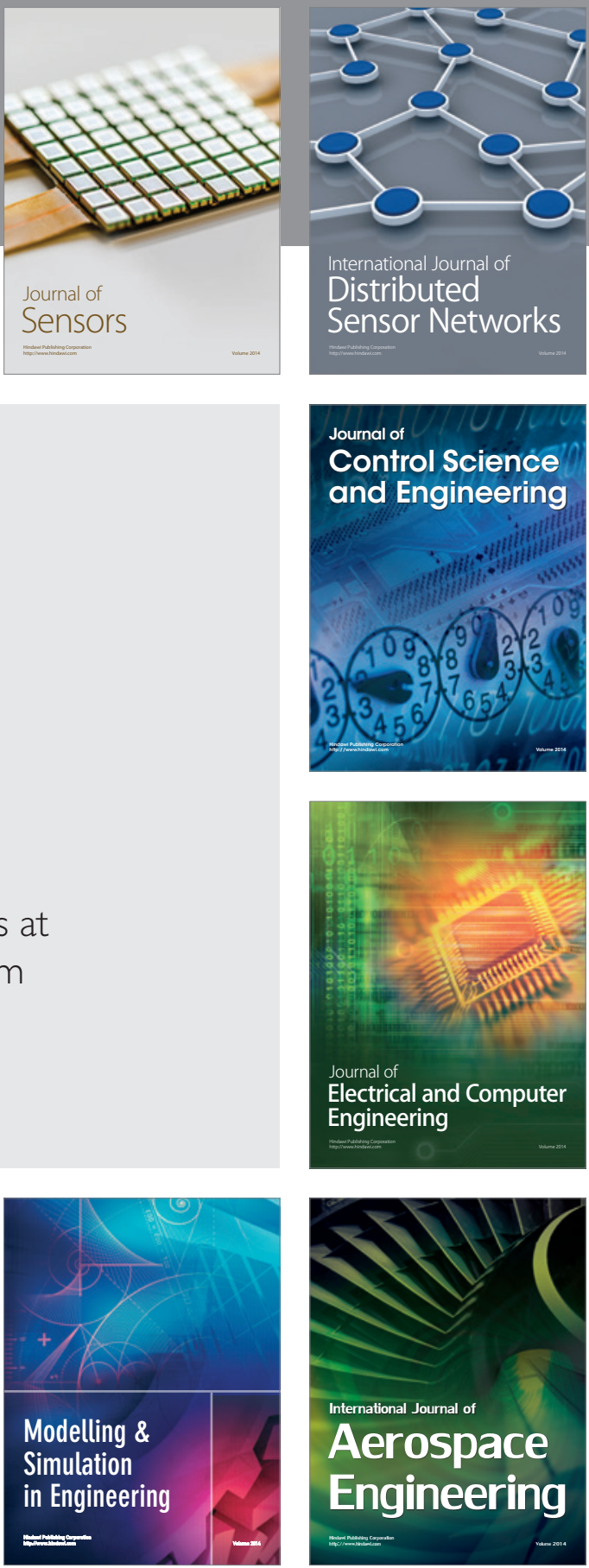

Journal of

Control Science

and Engineering
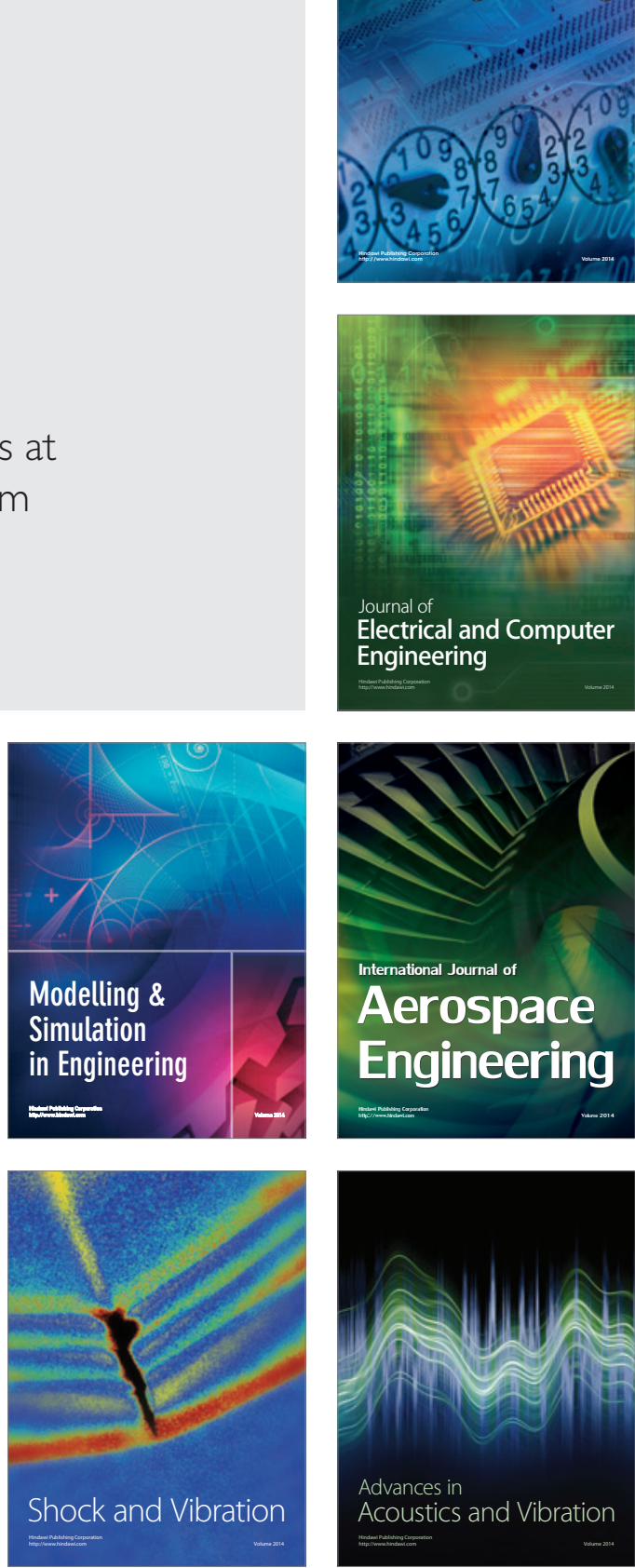